\title{
Buddhist and Psychological Perspectives on Emotions and Well-Being
}

\author{
Paul Ekman, ${ }^{1}$ Richard J. Davidson, ${ }^{2}$ Matthieu Ricard, ${ }^{3}$ and B. Alan Wallace ${ }^{4}$ \\ ${ }^{1}$ University of California, San Francisco; ${ }^{2}$ University of Wisconsin, Madison; ${ }^{3}$ Shechen Monastery, Katmandu, Nepal; and \\ Santa Barbara Institute for Consciousness Studies, Santa Barbara, California
}

\begin{abstract}
Stimulated by a recent meeting between Western psychologists and the Dalai Lama on the topic of destructive emotions, we report on two issues: the achievement of enduring happiness, what Tibetan Buddhists call sukha, and the nature of afflictive and nonafflictive emotional states and traits. A Buddhist perspective on these issues is presented, along with discussion of the challenges the Buddhist view raises for empirical research and theory.
\end{abstract}

KEYWORDS-Buddhism; consciousness

Buddhist thought, which arose more than 2,000 years ago in Asian cultures, holds assumptions that differ in important ways from modern psychology. The particular branch of Buddhist thinking we consider here is Indo-Tibetan, a tradition having roots in Indian thought and further developed by Tibetan theorists. It is a line of thinking that is more than 1,000 years old. Although different aspects of Buddhist thought have already influenced a number of psychologists, its challenges for research on emotion are not widely known. Some suggestive convergences between Buddhist thinking and, for example, findings in neurobiology, suggest the fruitfulness of integrating a Buddhist view into emotion research.

The traditional languages of Buddhism, such as Pali, Sanskrit, and Tibetan, have no word for "emotion" as such. Although discrepant from the modern psychological research tradition that has isolated emotion as a distinct mental process that can be studied apart from other processes, the fact that there is no term in Buddhism for emotion is quite consistent with what scientists have come to learn about the anatomy of

Address correspondence to Paul Ekman, P.O. Box 5211, Berkeley CA 94705; e-mail: paul@paulekman.com. the brain. Every region in the brain that has been identified with some aspect of emotion has also been identified with aspects of cognition (e.g., Davidson \& Irwin, 1999). The circuitry that supports affect and the circuitry that supports cognition are completely intertwined — an anatomical arrangement consistent with the Buddhist view that these processes cannot be separated.

We have chosen two issues, the achievement of enduring happiness and the nature of afflictive emotions, to illustrate the usefulness of considering the Buddhist perspective in work on emotion. Given the space allowed, we present illustrative examples of possible areas for research, rather than a more complete discussion.

This report is a collaborative effort of Buddhists (Matthieu Ricard and B. Alan Wallace) and psychologists (Paul Ekman and Richard J. Davidson). Our report grew out of an extraordinary meeting with His Holiness the Dalai Lama, in Dharamsala, India, in March 2000, that focused on destructive emotions. "The Buddhist authors wrote the sections titled "The Buddhist View," and the psychologist authors wrote the sections on research directions and theory.

\section{ACHIEVING ENDURING HAPPINESS}

The Buddhist View

Buddhists and psychologists alike believe that emotions strongly influence people's thoughts, words, and actions and that, at times, they help people in their pursuit of transient pleasures and satisfaction. From a Buddhist perspective, how-

\footnotetext{
${ }^{1}$ The participants at this meeting, besides the Dalai Lama, were Richard Davidson, Paul Ekman, Owen Flannagen, Daniel Goleman, Mark Greenberg, Thupten Jinpa, Matthieu Ricard, Jeanne Tsai, Francisco Varela, and Alan Wallace. We thank the Mind and Life Institute of Boulder, Colorado for organizing the meeting in India and a subsequent meeting during which we wrote this article.
} 
ever, some emotions are conducive to genuine and enduring happiness and others are not. A Buddhist term for such happiness is sukha, which may be defined in this context as a state of flourishing that arises from mental balance and insight into the nature of reality. Rather than a fleeting emotion or mood aroused by sensory and conceptual stimuli, sukha is an enduring trait that arises from a mind in a state of equilibrium and entails a conceptually unstructured and unfiltered awareness of the true nature of reality. Many Buddhist contemplatives claim to have experienced sukha, which increases as a result of sustained training.

Similarly, the Buddhist concept of duhkha, often translated as "suffering," is not simply an unpleasant feeling. Rather, it refers most deeply to a basic vulnerability to suffering and pain due to misapprehending the nature of reality. (The terms sukha and duhkha are from Sanskrit, one of the primary languages of Buddhist literature.)

How is sukha to be realized? Buddhists believe that the radical transformation of consciousness necessary to realize sukha can occur by sustained training in attention, emotional balance, and mindfulness, so that one can learn to distinguish between the way things are as they appear to the senses and the conceptual superimpositions one projects upon them. As a result of such training, one perceives what is presented to the senses, including one's own mental states, in a way that is closer to their true nature, undistorted by the projections people habitually mistake for reality.

Such training results not only in shifts in fleeting emotions but also leads to changes in one's moods and eventually even changes in one's temperament. For more than two millennia, Buddhist practitioners have developed and tested ways of gradually cultivating those emotions that are conductive to the pursuit of sukha and of freeing themselves from emotions that are detrimental to this pursuit. The ideal here is not simply to achieve one's own individual happiness in isolation from others, but to incorporate the recognition of one's deep kinship with all beings, who share the same yearning to be free of suffering and to find a lasting state of well-being.

\section{Two Research Directions}

We have begun to examine highly experienced Buddhist practitioners, who presumably have achieved sukha, to determine whether that trait manifests itself in their biological activity during emotional episodes (Lutz, Greischar, Rawlings, Ricard, \& Davidson, in press) or increases their sensitivity to the emotions of other people, and to see how their interactive style may transform the nature of conflictual interactions. Such study of Buddhism's most expert practitioners may change psychology's conception of what at least some human beings are capable of achieving.

Another possible area of research concerns the reliability of self-report about mental states. Although much of the research on emotion has presumed that research subjects and our patients during psychotherapy can readily report on their subjective experience through questionnaires and interviews, findings to date show that most people report only the most recent or most intense of their emotional experiences (e.g., Kahneman, Fredrickson, Schreiber, \& Redelmeier, 1993; Rosenberg \& Ekman, 1994) and are subject to bias. Research could determine whether those schooled in Buddhist practices could offer a more refined and complete account of their immediately past emotional experience, exhibiting fewer judgmental biases. In a related vein, other research has demonstrated that most people are poor predictors of what will make them happy (e.g., Wilson \& Gilbert, in press). It would be interesting to determine whether those who have engaged in Buddhist contemplative practices sufficiently to achieve sukha are more accurate in affective forecasting.

\section{AFFLICTIVE MENTAL STATES}

\section{The Buddhist View}

Buddhism does not distinguish between emotions and other mental processes. Instead, it is concerned with understanding which types of mental activity are truly conducive to one's own and others' well-being, and which ones are harmful, especially in the long run.

In Buddhism, a clear distinction is made between affective states that are directly aroused by the experience of pleasurable stimuli (sensory, as well as aesthetic and intellectual) and sukha, which arises from the attentional, emotional, and cognitive balance of the mind. (For a similar distinction, see Sheldon, Ryan, Deci, \& Kasser, 2004.) The experience of pleasure is contingent upon specific times, places, and circumstances, and can easily change into a neutral or unpleasant feeling. When one disengages from the pleasant stimulus, the resultant pleasure vanishes, whether or not it is connected to any afflictive state.

The initial challenge of Buddhist meditative practice is not merely to suppress, let alone repress, destructive mental states, but instead to identify how they arise, how they are experienced, and how they influence oneself and others over the long run. In addition, one learns to transform and finally free oneself from all afflictive states. This requires cultivating and refining one's ability to introspectively monitor one's own mental activities, enabling one to distinguish disruptive from nondisruptive thoughts and emotions. In Buddhism, rigorous, sustained training in mindfulness and introspection is conjoined with the cultivation of attentional stability and vividness.

In contrast to Aristotelian ethics, Buddhism rejects the notion that all emotions are healthy as long as they are not excessive or inappropriate to the time and place. Rather, Buddhism maintains that some mental states are afflictive regardless of their degree or the context in which they arise. Here we focus on three mental processes that are considered to be fundamental toxins of the mind. 
The first of these is craving. This mental process is based on an unrealistic, reified distinction between self and others-or between subject and object more generally-as being absolutely separate and unrelated. Craving is concerned with acquiring or maintaining some desirable object or situation for "me" and "mine," which may be threatened by "the other." One assumes that desirable qualities are inherent in the object desired and then exaggerates these qualities, while ignoring or deemphasizing that object's undesirable aspects. Craving is therefore an unrealistic way of engaging with the world, and it is harmful whenever one identifies with this afflictive mental process, regardless of how strong it is or the circumstances under which it arises. Craving is said to be afflictive, for it disrupts the balance of the mind, easily giving rise to anxiety, misery, fear, and anger; and it is unrealistic in the sense that it falsely displaces the source of one's well being from one's own mind to objects.

Hatred is the second of the fundamental afflictions of the mind and is a reverse reflection of craving. That is, hatred, or malevolence, is driven by the wish to harm or destroy anything that obstructs the selfish pursuit of desirable objects and situations for me and mine. Hatred exaggerates the undesirable qualities of objects and deemphasizes their positive qualities. When the mind is obsessed with resentment, it is trapped in the deluded impression that the source of its dissatisfaction belongs entirely to the external object (just as, in the case of craving, the mind locates the source of satisfaction in desirable objects). But even though the trigger of one's resentment may be the external object, the actual source of this and all other kinds of mental distress is in the mind alone.

The third, most fundamental affliction of the mind is the delusion of grasping onto one's own and others' reified personal identities as real and concrete. According to Buddhism, the self is constantly in a state of dynamic flux, arises in different ways, and is profoundly interdependent with other people and the environment. However, people habitually obscure the actual nature of the self by superimposing on reality the concepts of permanence, singularity, and autonomy. As a result of misapprehending the self as independent, there arises a strong sense of the absolute separation of self and other. Then, craving naturally arises for the "I" and for what is mine, and repulsion arises toward the other. The erroneous belief in the absolute distinction of self and other thus acts as the basis for the derivative mental afflictions of craving, hatred, jealousy, and arrogance. Such toxins of the mind are regarded, in Buddhism, as the sources of all mental suffering.

\section{Theoretical Issues and Research Directions}

Psychologists do not distinguish between beneficial and harmful emotions. Those who take an evolutionary view of emotion (e.g., Cosmides \& Tooby, 2000; Ekman, 1992) have proposed that emotions were adaptive over the history of the species and remain adaptive today. Even those who categorize emotions as simply positive or negative (e.g., Watson, Clark, \& Tellegen, 1988) do not propose that all of the negative emotions are harmful to oneself or to others. The goal in any psychologically informed attempt to improve one's emotional life is not to rid oneself of or transcend an emotion-not even hatred-but to regulate experience and action once an emotion is felt (Davidson, Jackson, \& Kalin, 2000). (Note, however, that not all theorists consider hatred an emotion.)

One point of convergence between the Buddhist and psychological perspectives is that hostility, which is viewed in the West as a character or personality trait, is considered to be destructive to one's health. Impulsive chronic violence is also considered to be dysfunctional and is classified as pathological (Davidson, Putnam, \& Larson, 2000). But neither of these is considered in psychology to be an emotion per se.

Rather than focusing on increasing consciousness of one's inner state, the emphasis in much of psychology is on learning how to reappraise situations (Lazarus, 1991) or how to control (regulate) emotional behavior and expressions (Gross, 1999; but see Ekman, 2003, for a psychological approach to enhancing awareness of emotions as they occur).

The growing literature based on self-report measures of wellbeing indicates that punctate events, even significant ones such as winning the lottery, phasically alter an individual's state of pleasure but do not change an individual's trait level of happiness. Buddhists agree that events such as winning the lottery would not alter an individual's dispositional level of happiness, but they do assert that happiness as a dispositional trait (sukha) can be cultivated through specific practices. Although the term trait positive affect as it has been used in the mood and temperament literature has some elements in common with sukha, it does not capture the essence of the Buddhist construct, which also includes a deep sense of well-being, a propensity toward compassion, reduced vulnerability to outer circumstances, and recognition of the interconnectedness with people and other living beings in one's environment. Moreover, sukha is a trait and not a state. It is a dispositional quality that permeates and pervades all experience and behavior.

Another important difference between Buddhism and psychological approaches is that the Buddhists provide a method for modifying affective traits and for cultivating sukha (Wallace, 2005), whereas in psychology the only methods for changing enduring affective traits are those that have been developed specifically to treat psychopathology. With a few notable exceptions (e.g., Seligman, 1998), no effort has been invested in cultivating positive attributes of mind in individuals who do not have mental disorders. Western approaches to changing enduring emotional states or traits do not involve the long-term persistent effort that is involved in all complex skill learningfor example, in becoming a chess master or learning to play a musical instrument. Typically, not even psychoanalysis or the most intensive forms of cognitive-behavior therapy involve the 
decades of training Buddhists consider necessary for the cultivation of sukha.

Buddhists, as we said, consider craving to be one of the primary toxins of the mind. Unlike psychologists, who restrict the idea of craving to states produced by substances of abuse or by strongly appetitive opportunities that offer the potential for abuse (e.g., gambling, sex), Buddhists use the term more generically to encompass the desire to acquire objects and situations for oneself. A growing body of neuroscientific literature has shown that activity of the neurotransmitter dopamine in a part of the brain called the nucleus accumbens is common to states of craving, including both pharmacologically induced addictions and activities such as gambling. Although activation of this system is highly reinforcing (i.e., it leads to the recurrence of behaviors associated with the system's activation), it is not associated with pleasure in the long run. Of course, what is not included in this neuroscientific framework is anything akin to the notion of sukha.

Buddhist contemplative practices are explicitly designed to counteract craving. It would thus be of great interest empirically to evaluate how effective these methods may be as interventions for addictive disorders, which are disorders of craving, and to determine if the brain systems associated with craving are altered by such training.

The Buddhist, but not Western, view considers hatred to be intrinsically harmful to people who experience it. This perspective suggests that it would be valuable to examine the different ways in which those who have been exposed to a major trauma react emotionally to the cause of their trauma-for example, how people whose children have been murdered react to the perpetrators once they are apprehended. In a study of such individuals, various biological, health, and social measures would provide information about the consequences of maintaining hatred or forgiveness toward the perpetrator.

\section{JOINT CONCLUSION}

Buddhist conceptions and practices that deal with emotional life make three very distinct contributions to psychology. Conceptually, they raise issues that have been ignored by many psychologists, calling on the field to make more finely nuanced distinctions in thinking about emotional experience. Methodologically, they offer practices that could help individuals report on their own internal experiences, and such practices might thereby provide crucial data that is much more detailed and comprehensive than that gathered by the techniques psychologists now use to study subjective emotional experience. Finally, Buddhist practices themselves offer a therapy, not just for the disturbed, but for all who seek to improve the quality of their lives. We hope what we have reported will serve to spark the interest of psychologists to learn more about this tradition.

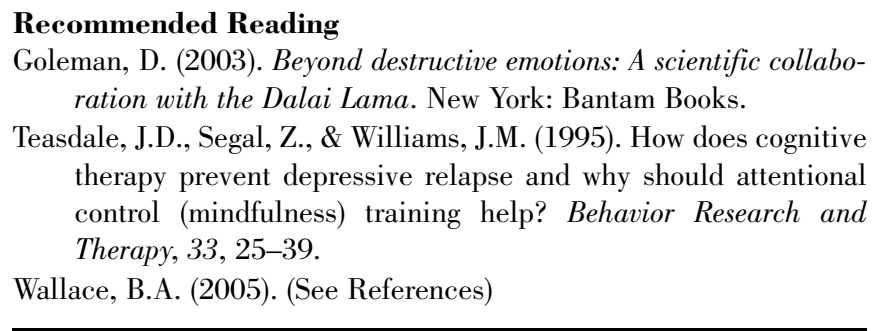

Acknowledgments-Paul Ekman's research was supported in part by a National Institute of Mental Health (NIMH) Senior Research Scientist Award, K05-MH06092. Richard Davidson's work described in this article has been supported by NIMH Grants MN43454, MH40747, P50-MH522354, and P50-MH61083; by NIMH Research Scientist Award K05MH00875; by grants from the Research Network on Mind-Body Interaction of the John D. and Catherine T. MacArthur Foundation; and by support from the University of Wisconsin. The authors are grateful to the many colleagues who read and gave helpful suggestions on earlier drafts of this article, but especially to Daniel Goleman.

\section{REFERENCES}

Cosmides, L., \& Tooby, J. (2000). Evolutionary psychology and the emotions. In M.L. Lewis \& J. Haviland-Jones (Eds.), Handbook of emotions (2nd ed., pp. 3-134). New York: Guilford Press.

Davidson, R.J., \& Irwin, W. The functional neuroanatomy of emotion and affective style. Trends in Cognitive Science, 3, 11-21.

Davidson, R.J., Jackson, D.C., \& Kalin, N.H. (2000). Emotion, plasticity, context and regulation: Perspectives from affective neuroscience. Psychological Bulletin, 126, 890-906.

Davidson, R.J., Putnam, K.M., \& Larson, C.L. (2000). Dysfunction in the neural circuitry of emotion regulation-a possible prelude to violence. Science, 289, 591-594.

Ekman, P. (1992). An argument for basic emotions. Cognition and Emotion, 6, 169-200.

Ekman, P. (2003). Emotions revealed: Recognizing faces and feelings to improve communication and emotional life. New York: Times Books.

Gross, J.J. (1999). The emerging field of emotion regulation: An integrative review. Review of General Psychology, 2, 271-299.

Kahneman, D., Fredrickson, B.L., Schreiber, C.A., \& Redelmeier, D.A. (1993). When more pain is preferred to less: Adding a better end. Psychological Science, 4, 401-405.

Lazarus, R. (1991). Emotion and adaptation. New York: Oxford University Press.

Lutz, A., Greischar, L.L., Rawlings, N.B., Ricard, M., \& Davidson, R.J. (in press). Long-term meditators self-induce high-amplitude gamma synchrony during mental practice. Proceedings of the National Academy of Sciences, USA.

Rosenberg, E.L., \& Ekman, P. (1994). Coherence between expressive and experiential systems in emotion. Cognition and Emotion, 8 , 201-229.

Seligman, M.E.P. (1998). Learned optimism. New York: Pocket Books. 
Sheldon, K.M., Ryan, R.M., Deci, E.L., \& Kasser, T. (2004). The independent effects of goal contents and motives on well-being: It's both what you pursue and why you pursue it. Personality and Social Psychology Bulletin, 30, 475-486.

Wallace, B.A. (2005). Genuine happiness: Meditation as the path to fulfillment. Hoboken, NJ: John Wiley and Sons.
Watson, D., Clark, L.A., \& Tellegen, A. (1988). Development and validation of brief measures of positive and negative affect: The PANAS scales. Journal of Personality and Social Psychology, $54,1063-1070$.

Wilson, T., \& Gilbert, D. (in press). Affective forecasting: Knowing what to want. Current Directions in Psychological Science. 